\title{
Rational Structural Designs for Highways in Different Climatic Zones in Sudan
}

\author{
Dr.Mohammed Mahmoud Shallal, Prof. Dr.Salih Elhadi Mohammed Ahmed \\ Sudan University of Science \& Technology
}

\begin{abstract}
This paper represents a pavement design guide for highways in Sudan. It is intended to provide a simple and easily applied method for determining an appropriate pavement structure for the expected design criteria. In this paper, detailed subgrade study, socio-economic study and axle loading \& traffic survey have been carried out. This is meant to provide reliable and first hand data. The main findings of this paper comprise: the Sudan subgrade soil study, the guides to choose the traffic growth rates, the trucks damage factors, the guides to arrive at the correct Equivalent Standard Axles in the design period Moreover, this paper produced a design catalogue that contain 308 pavement design section to be used in Sudan and anywhere in the globe as any other international pavement design catalogue.
\end{abstract}

Keywords: - subgrade soil, axle loads, equivalence factor, traffic growth rate, design period, pavement structural design)

\section{INTRODUCTION}

Pavement design is aimed at achieving a pavement structure which is economical and comfortable to the motorist; and which minimizes development of pavement distress features. Many design methods have been developed to suit different climatic and traffic loading conditions.

Flexible pavement design methods can be divided into Empirical and Semi- Empirical Pavement Design Methods and the Mechanistic-Empirical Design Methods which represents one step forward from empirical methods. One of the Mechanistic-Empirical Design Methods is the Asphalt Institute design method. ${ }^{(1)}$

\section{THE ASPHALT INSTITUTE DESIGN METHOD}

2.1 General: The Asphalt Institute design method allows for the influence of climate, or more specifically temperature, on pavement performance. The input data needed is the mean annual air temperature (MAAT) for the design site. The basis for subgrade strength measurement in this method is the subgrade resilient modulus $\left(\mathrm{M}_{\mathrm{r}}\right)$, which is an estimate of its modulus of elasticity. The $\mathrm{M}_{\mathrm{r}}$ is determined from the Tri-axial laboratory test in accordance with AASHTO Method T 307. In order to facilitate the use of other widely used tests, correlations have been established with the California Bearing Ratio (CBR) the stiffness test that widely used, and the Resistance $(\mathrm{R})$ value. Generally the steps of this design method are as follows:

- Determine initial traffic and expected growth rate, convert to EAL for design period.

- Measure or estimate subgrade (Mr): Suitable factors have been established to determine Mr from the

standard CBR and R-value tests.

- Select Materials.

- Determine design thickness combinations.

- Select final design.

The resulting thickness satisfy two different strain criteria, the vertical compressive strain at the surface of the subgrade, and horizontal tensile strain on the underside of the lowest asphalt-bound layer. Design thicknesses shown in the design charts; represent the greater of two thicknesses associated with the criteria. ${ }^{(2)}$

2.2 (SW-1) Design Software: The pavement design software (SW-1) of the Asphalt Institute has been used in determining the subgrade strength categories and the traffic loading classes. It has been used also to prepare the obtained standard pavement structural designs. ${ }^{(3)}$

III.

\section{DATA SURVEYS, COLLECTION AND ANALYSIS:}

3.1 Subgrade Soil Study:

Pavement is built to cover a large distance; the same road might be built over different types of subgrade materials with different properties. The change of subgrade properties requires different thicknesses of pavement layers in order to support the same traffic load and produce the same performance. The subgrade strength is the other most important factor, besides the traffic loading, which governs the pavement structural configuration $^{(4)}$. Since the CBR test is a fairly easy and widely used test in Sudan, it has been used to evaluate 
the subgrade properties. Based on the climatic zones criteria, soil survey has been carried out and 10 samples have been taken comprising; North East of Karima, South East of Abuhamad, Osaif, South west of Toker, West of Almatama, Kassala, 24 Elgurashi, Kadugli, Almujlad and Algadarif covering the climatic zones of Sudan that comprise Desert, Semi Desert, Dry and Semi Humid. Tests conducted on the samples comprised Gradation, Atterberg Limits (Liquid Limit, Plastic Limit, and Plasticity Index), Compaction Test and CBR Test. ${ }^{(5)}$

Table (1): Results of Subgrade Study

\begin{tabular}{|c|c|c|c|c|}
\hline \multirow[t]{2}{*}{ No. } & \multirow[t]{2}{*}{ Sample Location } & \multicolumn{3}{|c|}{ CBR@ } \\
\hline & & $\begin{array}{c}90 \\
\% \mathrm{MDD}\end{array}$ & $\begin{array}{c}95 \\
\% \mathrm{MDD}\end{array}$ & $100 \% \mathrm{MDD}$ \\
\hline 1 & North East of Karima & 22.0 & 26.0 & 30.0 \\
\hline 2 & South East of Abuhamad & 8.0 & 13.0 & 19.0 \\
\hline 3 & Osaif & 38.0 & 44.0 & 51.0 \\
\hline 4 & South west of Toker & 20.0 & 26.0 & 36.0 \\
\hline 5 & West of Almatama & 10.0 & 21.0 & 25.0 \\
\hline 6 & Kassala & 12.0 & 17.0 & 26.0 \\
\hline 7 & 24 Elgurashi & 2.0 & 3.3 & 4.0 \\
\hline 8 & Kadugli & 5.0 & 7.0 & 7.5 \\
\hline 9 & Almujlad & 4.0 & 5.7 & 6.5 \\
\hline 10 & Algadarif & 2.0 & 2.7 & 3.2 \\
\hline
\end{tabular}

\subsection{Growth Rate Study:}

Pavements must be designed to adequately serve traffic needs over a period of years. Traffic growth - and in some cases, no growth or decline - must, therefore, be anticipated when determining the structural requirements of the pavement. ${ }^{(6)}$

3.2.1 Socio-Economic Factors: All over the world, the socio-economic factors are used as predictors by using the data in developing of models. The socio-economic data include; population, earnings, employment, income. (7)

3.2.1.1 Gross Domestic Product (GDP) Growth Indicator: In the absence of precise information about traffic growth rates obtained from studies of origin and destination, regression models, population growth, households income, land use, vehicles ownership, number of vehicles registered, fuel consumption...etc the data for GDP growth rates is the most important one for the estimations of traffic growth rate ${ }^{(7)}$. For our case and for the absence of all mentioned above, the GDP growth rates for the years from 1991 to 2010 have been taken from the records of the Ministry of Finance and National Economy ${ }^{(\mathbf{8})}$. These data have good contribution to the determination of the traffic growth rates. These data have presented in table (1) and figure (1) below:

Table (2): GDP Growth in Sudan from 1991 to 2010

\begin{tabular}{|c|c|c|c|}
\hline Year & GDP Growth Rate\% & Year & GDP Growth Rate\% \\
\hline 1991 & 7 & 2002 & 5 \\
\hline 1992 & 7 & 2003 & 5.8 \\
\hline 1993 & 4 & 2004 & 6 \\
\hline 1994 & 2 & 2005 & 6.2 \\
\hline 1995 & 9 & 2006 & 6.3 \\
\hline 1996 & 4 & 2007 & 6.4 \\
\hline 1997 & 7 & 2008 & 6 \\
\hline 1998 & 8 & 2009 & 5 \\
\hline 1999 & 5 & 2010 & 2.8 \\
\hline 2000 & 7 & 2011 & 2 \\
\hline 2001 & 5.8 & 2012 & \\
\hline
\end{tabular}




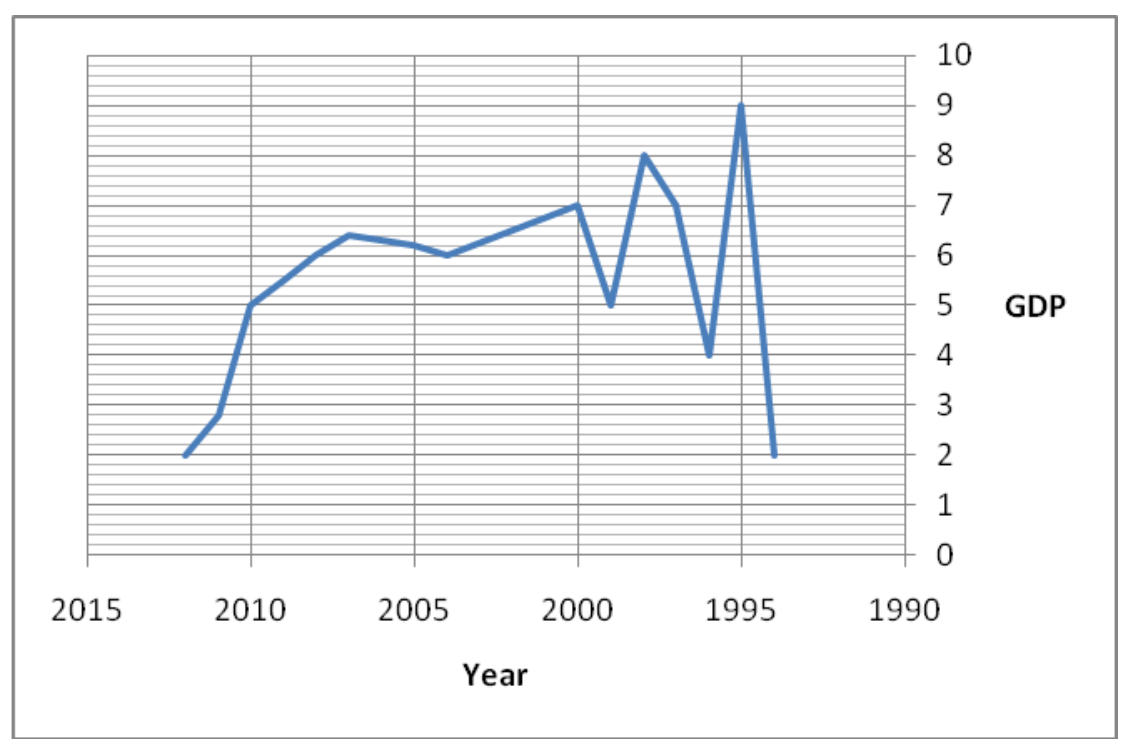

Figure (1): GDP \% (1991-2012)

In Sudan the prediction of traffic growth rate is a difficult task due to many reasons like unavailability of annual traffic counts by the responsible authorities. The fluctuation in the economic situation is very high. There is unavailability of transport models and correct data for numbers of registered vehicles. No strategies and plans and no sources for information about transport prices and trends, land use, employment levels.

To forecast the traffic growth rate, the guidance given in Kenya Pavement Design Manual has been followed ${ }^{(9)}$. In accordance with Kenya experience in determining the annual traffic growth rate in absence of precise information, it is recommended that the annual growth rate is between 1 and 2 times the GDP. In Sudan the 5\% annual growth rate has been used by many pavement design engineers, without taking in consideration the factors affect this percentage from a year to another. We should take into account that there is no certain source for such information. The usage of a rate that is less than actual means obtaining of weak design sections that will not last for the period determined in design. In the other hand, using of high percent may give uneconomical designs. This simplistic and effective approach of Kenya could be used for the availability of GDP data. In this regard, the Road Note No.31 says the following: (As an alternative to time, growth can be related linearly to anticipate Gross Domestic Product (GDP). This is normally preferable since it explicitly takes into account changes in overall economic activity. Whatever the forecasting procedure used, it is essential to consider the realism of forecast future levels. Few developing countries are likely to sustain the high rate of growth experienced in the past) Undoubtedly the range of 1 to 2 of the GDP itself is very wide, and therefore should be evaluated in order to arrive at realistic guidance. Using a factor of 1 times the GDP is the most reasonable and realistic approach. It has been found that the annual growth rate is between 5\% and 7\% for the years from 2000 to 2010. For the purpose of this paper, and in order to create scenarios for the traffic loading on highways, three annual growth rates has been proposed namely $5 \%, 6 \%$ and $7 \%$. These scenarios are needed to predict the limits that the traffic loading may reach it in our highway network, then to prepare standard designs that consider these limits.

\subsection{The Traffic and Axle Loading Data:}

3.3.1 General: Reliable traffic information for pavement design is most important stage in pavement design. The main problem faces roads design and maintenance in the Sudan is the incompatibility between traffic projections, pavement design and axle load control. The axle loads to be considered in design should be the legal axle loads determined for each road class of roads. The related previous studies carried out in Sudan did not solve the problem of pavement design in Sudan. These studies are:

1. Truck Operating Characteristics in the Sudan (1982-1983) by the Roads and Bridges Public Corporation of the Ministry of Construction and Public Works in collaboration with the Ministry of Finance and Economic Planning. ${ }^{(10)}$

2- Highway Organization and Investment Study (HOIS) by Newtech Consulting Group (Sudan) and Nor Consult (Norway). ${ }^{(11)}$

3- Pavement Management System for Sudan, 1994, by Newtech Consulting Group. ${ }^{(12)}$

4- Axle Load Control Study, 1999, by (Ashraf\&Salah Consultants). ${ }^{(13)}$ 
Now Sudan has made considerable efforts towards the total application for Laws of the Common Market for Eastern and Southern Africa (COMESA). So using the axle load limits of COMESA, equivalence factors for trucks of the types used in Sudan have been calculated.

Table (3): COMESA axle load limits ${ }^{(14)}$

\begin{tabular}{|c|c|}
\hline Type of Axle & Load (Ton) \\
\hline Single Steering Axle & 8 \\
\hline Drive Axle & 10 \\
\hline Tandem Axle Group & 16 \\
\hline Triple Axle Group & 24 \\
\hline
\end{tabular}

3.3.2 Trucks Equivalence Factors: - To determine types of trucks that working in Sudan, a two days survey for this purpose has been carried out in Khartoum and Port Sudan. These equivalence factors (damage factors) for the various trucks have been prepared to help avoiding the mistakes always arise from the wrong understanding and calculating of the trucks equivalence factors which affect as a result the number of axles predicted over the selected design period.

Table (4): Trucks Equivalence Factors ${ }^{(\mathbf{1 5})}$

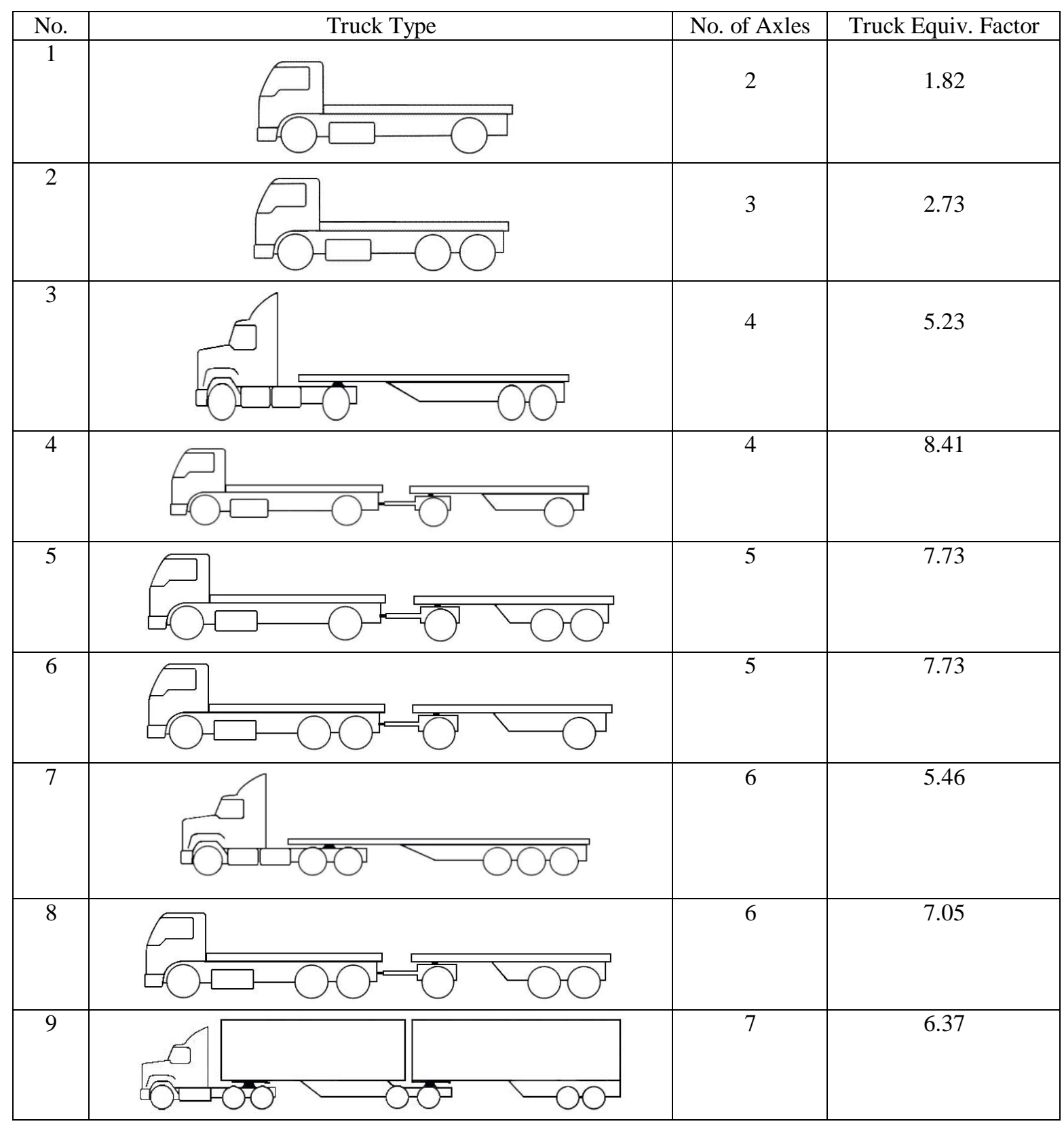




\begin{tabular}{|c|c|c|c|}
\hline 10 & 1 & 8 & 7.28 \\
\hline 11 & $\square$ & 9 & 11.37 \\
\hline 12 & & 9 & 8.19 \\
\hline 13 & & 11 & 10.01 \\
\hline
\end{tabular}

3.3.3 Traffic Survey at National Highways and the Loading Scenarios: For the purpose of this paper, a traffic survey conducted at 8 highways. These highways comprise Khartoum - Atbara, Khartoum - Madani, Khartoum - Rabak, Kosti - Elobeid, Sinnar - Rabak, Port Sudan - Hiya, Al-Gadarif - Kassala and Omdurman - Almultaga Roads. The loading scenarios are as follows:

(1) The first Scenario (5\% Growth Rate):

Table (5): Total Loading first Scenario

\begin{tabular}{|r|c|r|c|c|c|}
\hline No. & Road Name & ESA / Day & \multicolumn{3}{|c|}{$\begin{array}{c}\text { ESA } \\
\text { (million) }\end{array}$} \\
\cline { 4 - 6 } & & & 10 Years & 15 Years & 20 Years \\
\hline 1 & Khartoum - Atbara & 2394 & 11 & 18.9 & 28.9 \\
\hline 2 & Khartoum - Madani & 2836 & 13 & 22.3 & 34.2 \\
\hline 3 & Khartoum - Rabak & 2367 & 10.9 & 18.6 & 28.6 \\
\hline 4 & Kosti - Elobeid & 1923 & 8.8 & 15.1 & 23.2 \\
\hline 5 & Sinnar - Rabak & 1127 & 5.2 & 8.9 & 13.6 \\
\hline 6 & PortSudan - Hiya & 2691 & 12.4 & 21.2 & 32.5 \\
\hline 7 & Gadarif Kassala & 1058 & 4.9 & 8.3 & 12.8 \\
\hline 8 & Omdurman - Almltaga & 721 & 3.3 & 5.7 & 8.7 \\
\hline
\end{tabular}

(2) The second scenario (6\% Growth Rate):

Table (6): Total Loading second scenario

\begin{tabular}{|r|r|r|c|c|c|}
\hline No. & Road Name & ESA / Day & \multicolumn{3}{|c|}{$\begin{array}{c}\text { ESA } \\
\text { (million) }\end{array}$} \\
\cline { 4 - 6 } & & & 10 Years & 15 Years & 20 Years \\
\hline 1 & Khartoum - Atbara & 2394 & 11.5 & 20.3 & 32.1 \\
\hline 2 & Khartoum - Madani & 2836 & 13.6 & 24.1 & 38.1 \\
\hline 3 & Khartoum - Rabak & 2367 & 11.4 & 20.1 & 31.8 \\
\hline 4 & Kosti - Elobeid & 1923 & 9.3 & 16.3 & 25.8 \\
\hline 5 & Sinnar - Rabak & 1127 & 5.4 & 9.6 & 15.1 \\
\hline 6 & PortSudan - Hiya & 2691 & 12.9 & 22.9 & 36.1 \\
\hline 7 & Gadarif Kassala & 1058 & 5.1 & 9 & 14.2 \\
\hline 8 & Omdurman - Almltaga & 721 & 3.5 & 6.1 & 9.7 \\
\hline
\end{tabular}

(3)The Third Scenario (7 \% Growth Rate):

Table (7): Total Loading third Scenario

\begin{tabular}{|r|r|r|r|r|r|}
\hline No. & Road Name & \multirow{2}{*}{ ESA / Day } & \multicolumn{3}{|c|}{$\begin{array}{c}\text { ESA } \\
\text { (million) }\end{array}$} \\
\cline { 4 - 6 } & & & 10 Years & 15 Years & 20 Years \\
\hline 1 & Khartoum - Atbara & 2394 & 12.1 & 22 & 35.8 \\
\hline
\end{tabular}




\begin{tabular}{|r|r|r|r|r|r|}
\hline 2 & Khartoum - Madani & 2836 & 14.3 & 26 & 42.4 \\
\hline 3 & Khartoum - Rabak & 2367 & 11.9 & 21.7 & 35.4 \\
\hline 4 & Kosti - Elobeid & 1923 & 9.7 & 17.6 & 28.8 \\
\hline 5 & Sinnar - Rabak & 1127 & 5.7 & 10.3 & 16.9 \\
\hline 6 & Port Sudan - Hiya & 2691 & 13.6 & 24.7 & 40.3 \\
\hline 7 & Gadarif Kassala & 1058 & 5.3 & 9.7 & 15.8 \\
\hline 8 & Omdurman - Almltaga & 721 & 3.6 & 6.6 & 10.8 \\
\hline
\end{tabular}

4. Determination of Subgrade Strength Categories and Traffic Loading Classes: The SW-1 ${ }^{(\mathbf{3})}$ has been used to determine the correct subgrade strength categories. One Equivalent Standard Axle Load (ESAL) of 700506 has been used with different subgrade strengths range from $(C B R=3$ to $C B R=19, M r=31$ to $M r=196)$. Since the design software works using the Resilient Modulus to indicate the subgrade strength, the Asphalt Institute correlations have been used to convert between the CBR and Mr.

\begin{tabular}{|c|c|c|c|c|c|c|c|}
\hline Category & A & B & C & D & E & F & G \\
\hline CBR & $\geq 30$ & $15-29$ & $11-14$ & $8-10$ & $6-7$ & $4-5$ & $\leq 3$ \\
\hline
\end{tabular}

Then constant subgrade resilient modulus of 51.1 $\mathrm{MPa}(\mathrm{CBR}=5)$ has been selected to observe the differences on the pavement design section when changing the traffic loading.

\begin{tabular}{|c|c|c|c|c|c|c|}
\hline Class & T1 & T2 & T3 & T4 & T5 & T6 \\
\hline ESA $\left(10^{6}\right)$ & $\leq 1$ & $1-2$ & $\mathbf{2 - 3}$ & $\mathbf{3 - 4}$ & $\mathbf{4 - 6}$ & $\mathbf{6 - 1 0}$ \\
\hline Class & T7 & T8 & T9 & T10 & T11 & - \\
\hline ESA $\left(10^{6}\right)$ & $\mathbf{1 0 - 1 5}$ & $\mathbf{1 5 - 2 0}$ & $\mathbf{2 0 - 3 0}$ & $\mathbf{3 0 - 4 0}$ & $\geq 40$ & - \\
\hline
\end{tabular}

\section{The Developed Standard Pavement Structural Designs:}

Using the Asphalt Institute pavement design software (SW-1) ${ }^{(3)}$, standard pavement structural designs have been prepared for each of traffic loading classes with each of the subgrade strength categories.

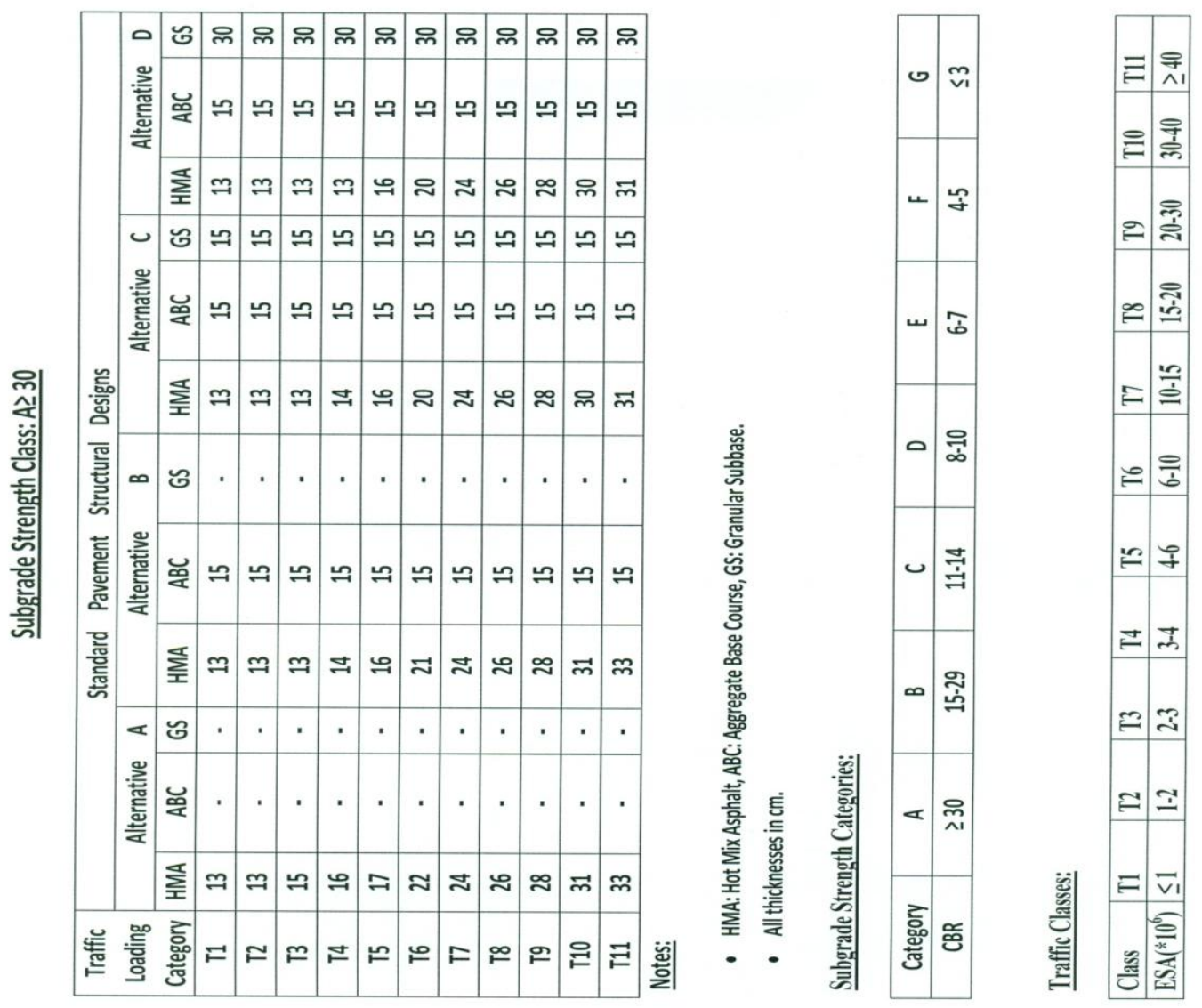




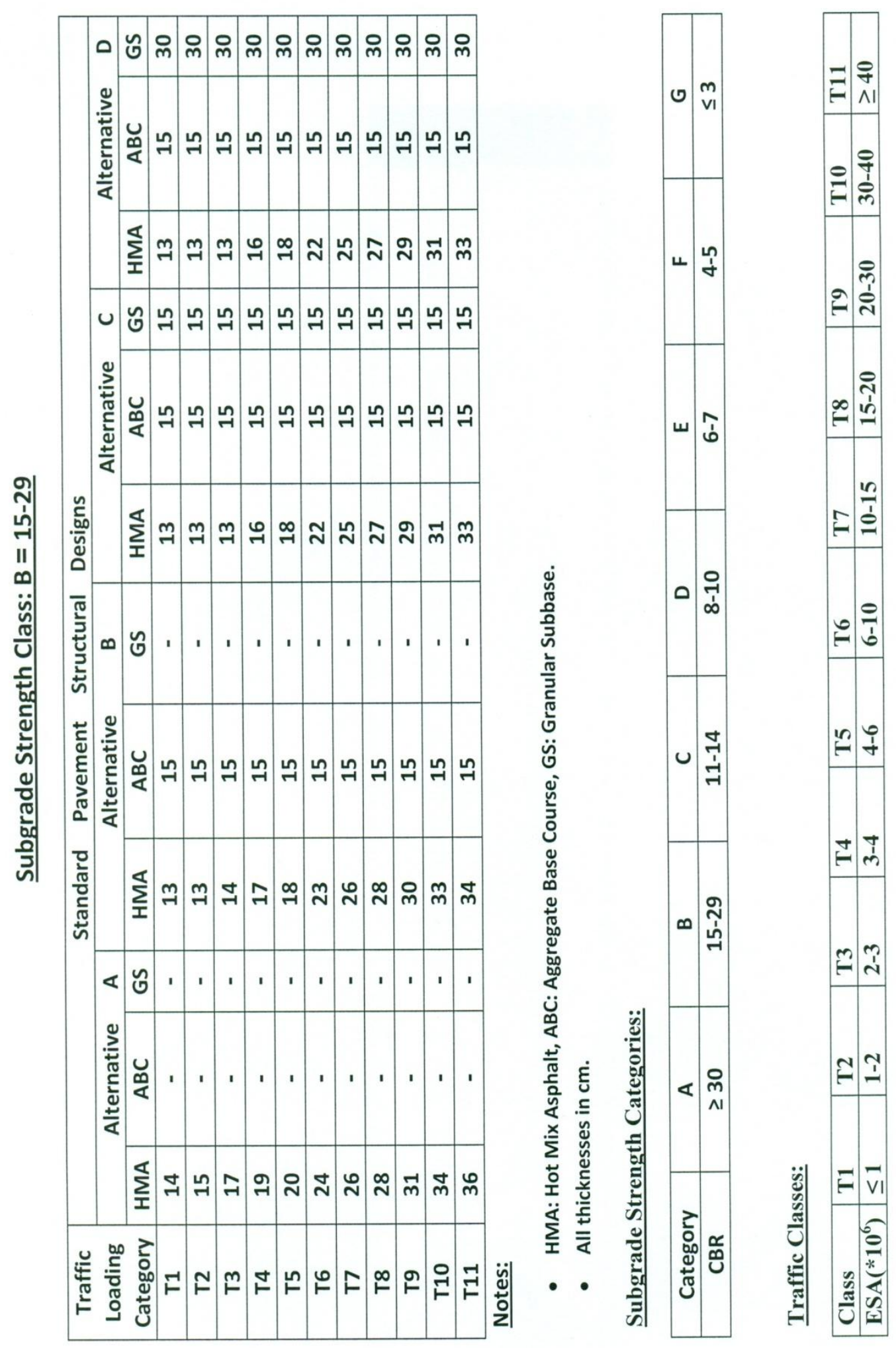




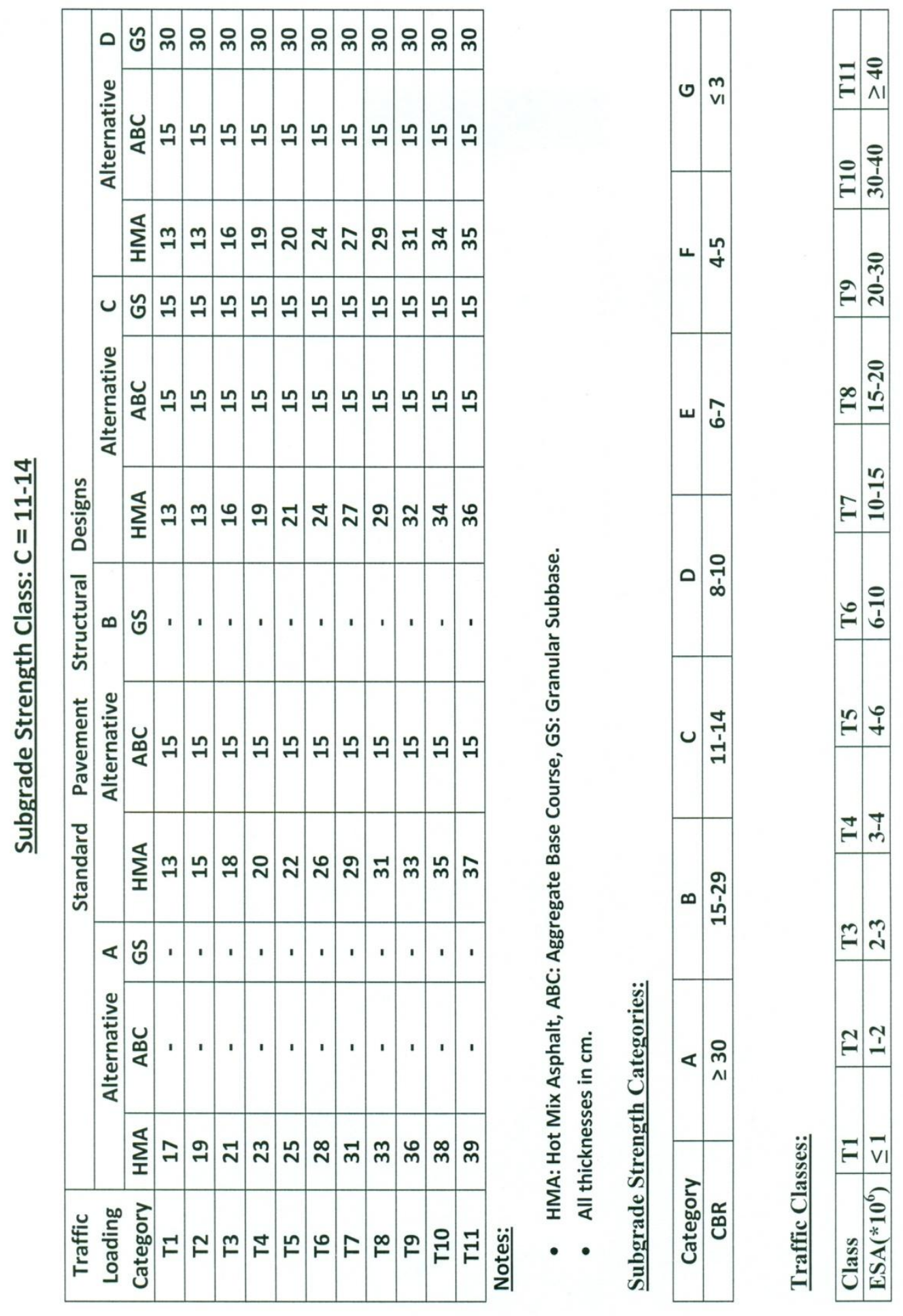




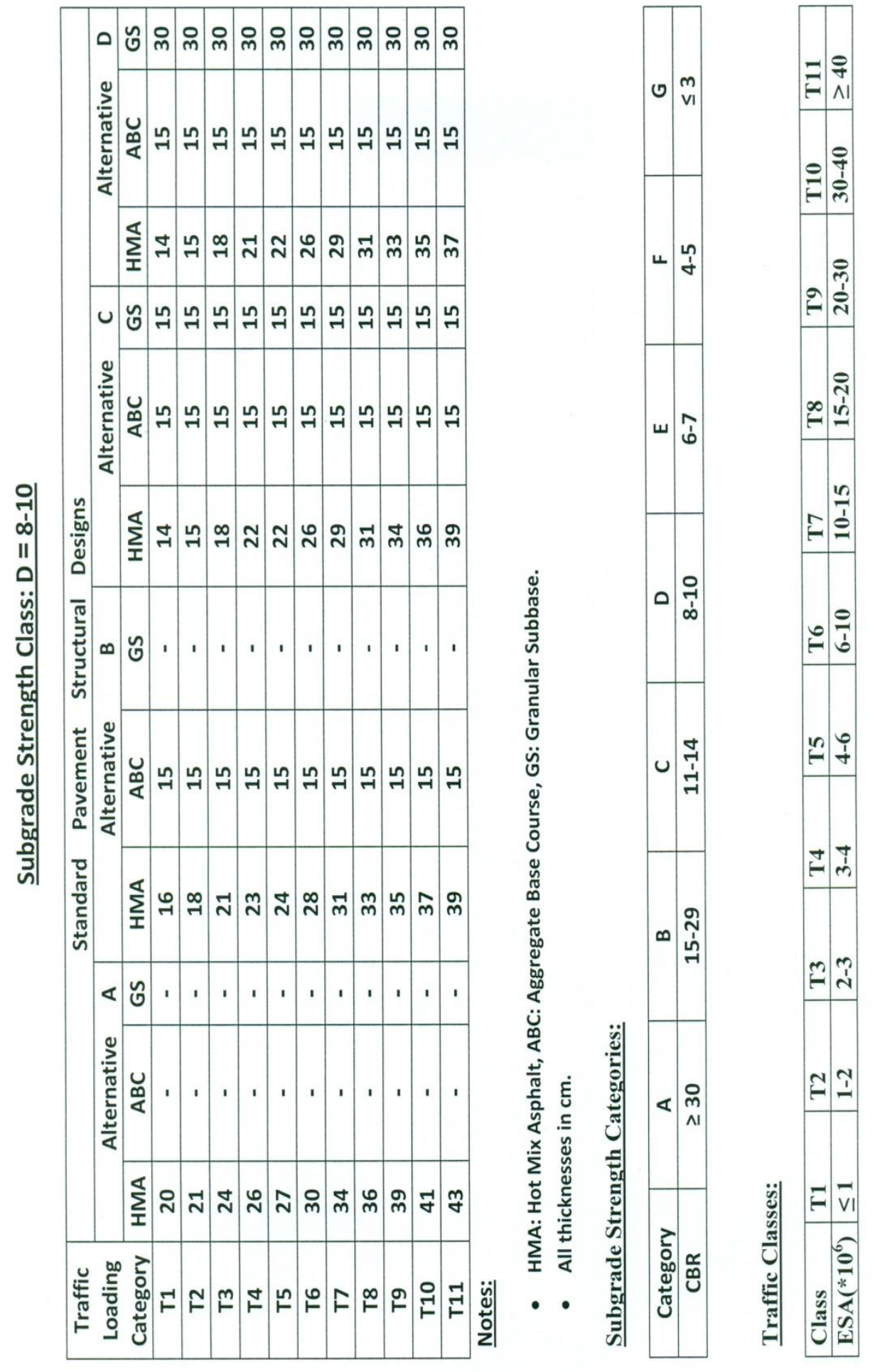



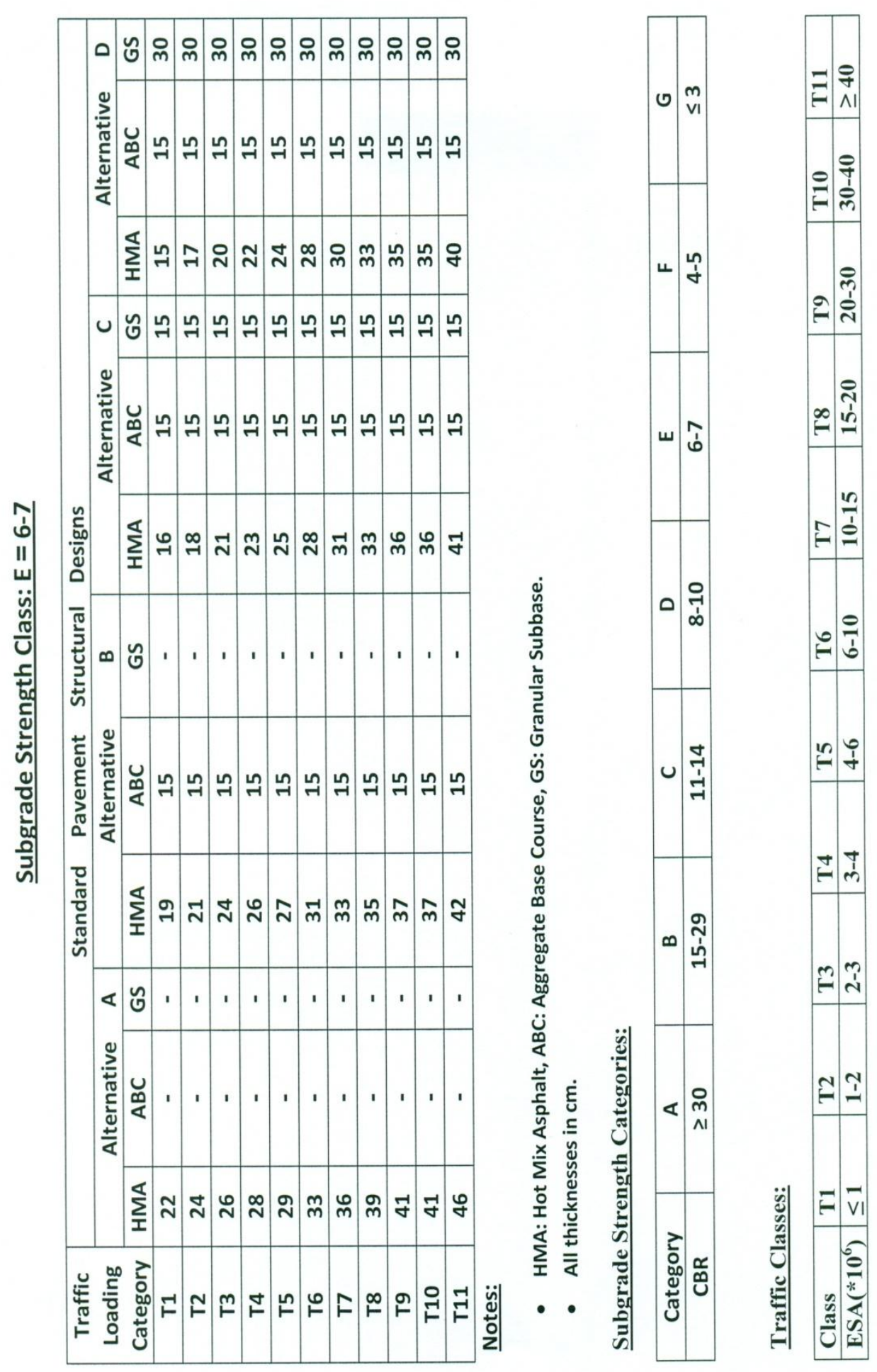

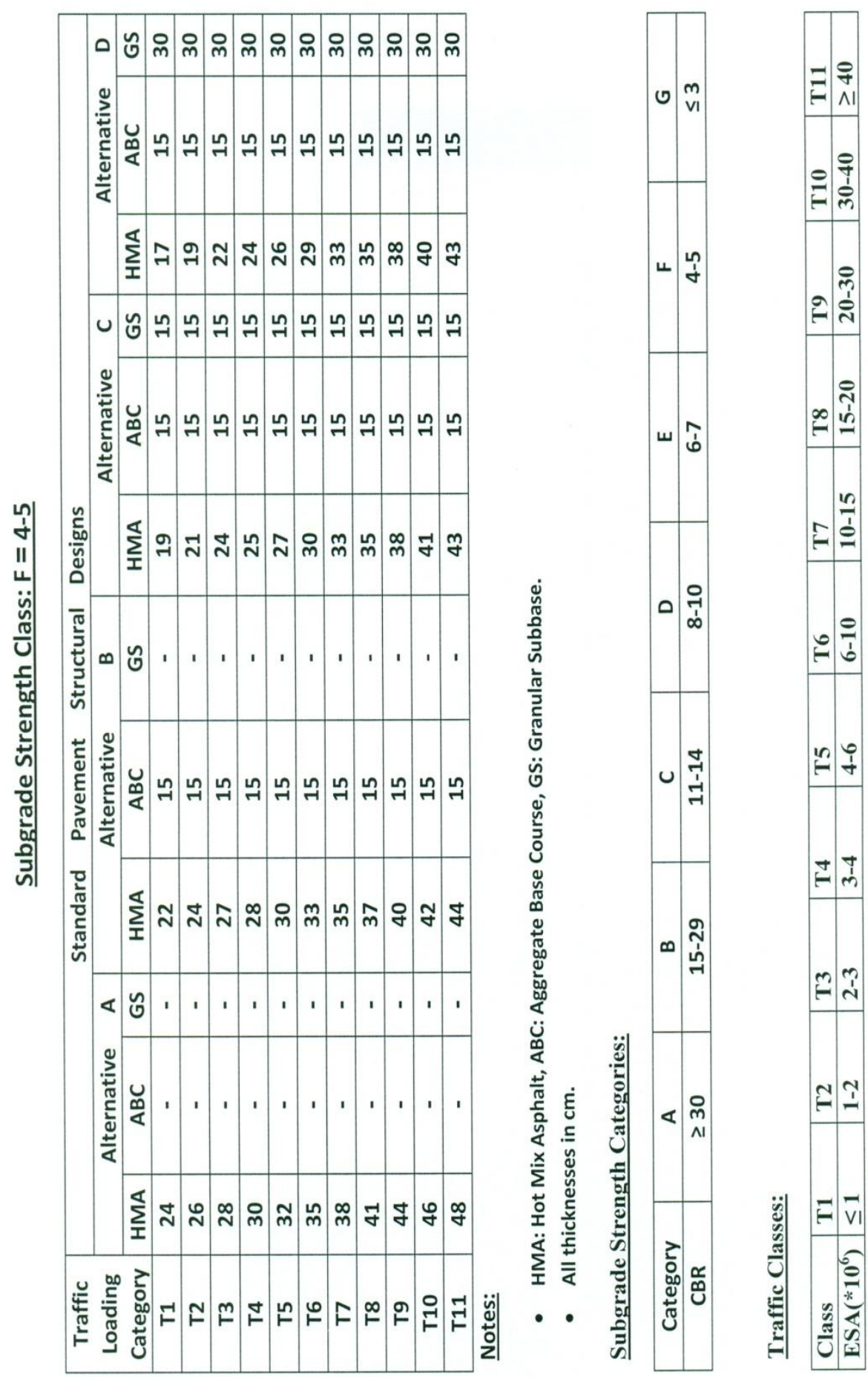

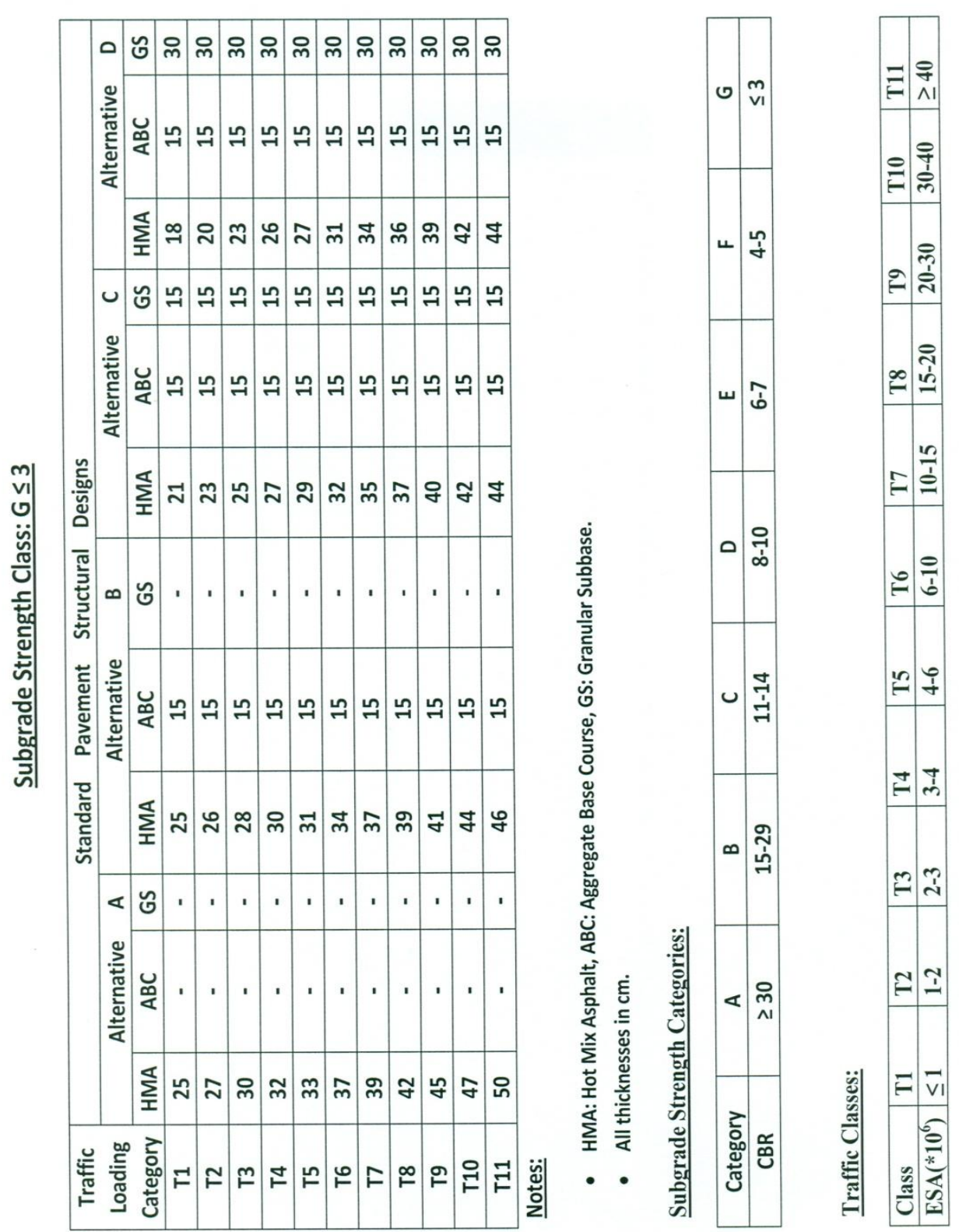

CONCLUSION

The earlier sections have provided guidance to the designer in selecting the design parameters of design period, traffic growth rates, traffic class, and subgrade support. These are the primary factors used in entering the standard designs catalogue. The following steps conclude the design procedure:

- Select or determine input data:

$>$ Traffic value, EAL.

$>$ Subgrade strength, CBR.

$>$ Surface and base types.

- Determine design thickness for the specific conditions described by the input data.

- Make an economic analysis of the various solutions arrived at for the design problem.

- Select final design. 


\section{RECOMMENDATIONS}

Based on the findings of this research, it is recommended that:

$>$ A maximum design life of 20 years is recommended.

$>$ Asphalt bases have many advantages over untreated base courses, especially in resisting pavement stresses. And asphalt bases are excellent for stage construction.

> The roads and highways authorities should carry out traffic surveys at the national roads to collect data on annual basis about heavy traffic, its composition, configurations, numbers and axle loads.

$>$ The challenge of overloading control is one of the most important roads sector issues in Sudan. The issue of vehicle.

> Reducing the asphalt concrete thickness by using very large thickness of untreated aggregate should be avoided. It is discouraged by the Asphalt Institute because the potential for other pavement problems will increase.

> Maintenance for Road Networks: Maintenance contracts should be used to award the work to Maintenance Contractors through tendering to ensure that there will be effective maintenance for the road network and that there is some body responsible for these works at time. These contracts should cover all the forms of maintenance routine, recurrent, periodic and urgent maintenance.

$>$ Highway Research: Highway Research Program is highly needed to put the guides for solving the problems of highway engineering and industry in Sudan and making significant advances in traditional highway engineering and technology by concentrating the research in specific technical areas.

> Stage Construction: Stage Construction is not recommended for heavy traffic, especially overloaded axles, as the risks of premature deteriorations are unacceptable for such important roads.

\section{REFERENCES}

[1]. T.F.FWA, 2006, The Handbook of Highway Engineering.

[2]. Asphalt Institute, 2008, Asphalt Pavements for Highways \& Streets, Manual Series No.1 (MS-1), 9th edition, Lexington, KY, USA.

[3]. Asphalt Institute, 2005, User' Guide for Asphalt Pavement Design Software for Highways, Airports, Heavy Wheel Loads and other applications (SW-1).

[4]. Colm AO' Flaherty, 2002, (Highways, the Location, Design, Construction and Maintenance of Pavements), $4^{\text {th }}$ edition.

[5]. American Association of State Highways and Transportation Officials (AASHTO), 2012, Standard Specifications for Transportation Materials and Methods of Sampling and Testing, USA.

[6]. TRL, 1993, Road Note 31: A guide to the structural design of bituminous surfaced roads in tropical and sub-tropical countries, 4th edition, London.

[7]. Department of Transportation, State of Florida, 2012, Project Traffic Forecasting Handbook.

[8]. Records of Sudan Ministry of Finance (1991-2010).

[9]. Kenya Ministry of Transport and Communication, 1995, Road Design Manual, Kenya.

[10]. Sudan National Corporation of Roads and Bridges, Truck Operating Characteristics in the Sudan (1982-1983).

[11]. Newtech and Nor-consult Joint venture, 1987, Highway Organization and Investment Study, Sudan.

[12]. Newtech Engineering \& Industrial Group, 1994, Pavement Management System for Sudan.

[13]. Ashraf\&Salah Consulting Engineers, 1999, Axle Load Control Study for Western Salvation Road, Volume (1), Sudan.

[14]. COMESA website, (www.comesa.int ), December 2009.

[15]. Mohammed Mahmoud Shallal, 2010, paper on: Traffic Loading for Pavement Design, published by Journal of Building and Road Research, volume 9, Building \& Road Research Institute, University of Khartoum, Sudan.

[16]. Yang H.Huang (2004), Pavement Analysis and Design.

[17]. TRL, 1970, Road Note 29 (RN 29): A guide to the structural design of flexible and rigid pavements for new roads, 3rd edition, London.

[18]. Texas Department of Transportation (TxDOT), 2011, Pavement Design Guide, published by Texas Department of Transportation.

[19]. AASHTO (1993), Guide for the Design of Pavement Structures, American Association of State Highway and Transportation Officials, Washington, D.C.

[20]. Department of Civil and Environmental Engineering, the University of Marland, 2007, Implementation of the NCHRP 1-37A Design Guide, Final Report, Volume 2, Evaluation of Mechanistic-Empirical Design Procedure. 
[21]. George B. Sowers, 1979, Introductory Soil Mechanics and Foundations: Geotechnical Engineering, 4th Edition, Macmillan Publishing Co., Inc., New York, Collier Macmillan Publishers, London.

[22]. Sudan Central Bureau of Statistics.

[23]. The Federation of Eastern and Southern African Roads Transport Association (FESARTA), 2010, Axle Mass Vehicle Combination Load limits in East and Southern Africa.

[24]. Sudan Ministry of Roads and Bridges, National Highway Authority, 2001, Axle Load Study.

[25]. TRRL, 2004, Road Note 40: A guide to axle load surveys and traffic counts for determining traffic loading on pavements, 1st edition, London.

[26]. The Asphalt Institute, 1982, Research and Development of the Asphalt Institute's Thickness Design Manual (MS-1), ${ }^{\text {th }}$ Edition, Research Report 82-2. 